\title{
TAP-independent self-peptides enhance T cell recognition of immune-escaped tumors
}

\author{
Elien M. Doorduijn, ${ }^{1}$ Marjolein Sluijter, ${ }^{1}$ Bianca J. Querido, ${ }^{1}$ Cláudia C. Oliveira, ${ }^{1}$ Adnane Achour, ${ }^{2}$ Ferry Ossendorp, ${ }^{3}$ \\ Sjoerd H. van der Burg, ${ }^{1}$ and Thorbald van Hall' \\ 'Department of Clinical Oncology, Leiden University Medical Center (LUMC), Leiden, Netherlands. 2Science for Life Laboratory (ScilifeLab), Department of Medicine, Solna, Karolinska Institutet, \\ Stockholm, Sweden. ${ }^{3}$ Department of Immunohematology and Blood Transfusion, LUMC, Leiden, Netherlands.
}

\begin{abstract}
Tumor cells frequently escape from CD8 ${ }^{+} \mathrm{T}$ cell recognition by abrogating $\mathrm{MHC}-\mathrm{I}$ antigen presentation. Deficiency in processing components, like the transporter associated with antigen processing (TAP), results in strongly decreased surface display of peptide/MHC-I complexes. We previously identified a class of hidden self-antigens known as T cell epitopes associated with impaired peptide processing (TEIPP), which emerge on tumor cells with such processing defects. In the present study, we analyzed thymus selection and peripheral behavior of T cells with specificity for the prototypic TEIPP antigen, the "self" TRH4 peptide/ $D^{b}$ complex. TEIPP T cells were efficiently selected in the thymus, egressed with a naive phenotype, and could be exploited for immunotherapy against immune-escaped, TAP-deficient tumor cells expressing low levels of MHC-I (MHC-I')). In contrast, overt thymus deletion and functionally impaired TEIPP T cells were observed in mice deficient for TAP1 due to TEIPP antigen presentation on all body cells in these mice. Our results strongly support the concept that TEIPPs derive from ubiquitous, nonmutated self-antigens and constitute a class of immunogenic neoantigens that are unmasked during tumor immune evasion. These data suggest that TEIPP-specific CD8 ${ }^{+}$T cells are promising candidates in the treatment of tumors that have escaped from conventional immunotherapies.
\end{abstract}

\section{Introduction}

Cytotoxic $\mathrm{CD}^{+} \mathrm{T}$ cells are key players of the immune system that kill virus-infected and cancerous cells by sensing the state of the cellular proteome. A major focus of current studies in the field of cancer immunotherapy is the activation (and reactivation) of tumor-specific $\mathrm{T}$ cells, by means of vaccination with tumor-specific antigens, transfer of in vitro-activated tumor infiltrating $\mathrm{T}$ cells, and blockade of inhibitory molecules such as CTLA-4 and PD-1 (1-4). Impressive results have been obtained in improvement of patient survival and regressions of cancer lesions, emphasizing the importance of $\mathrm{T}$ cells for therapeutic efficacy. Several classes of tumor-specific antigens have been characterized. Highly immunogenic tumor-specific antigens include viral antigens in HPV-induced cervical carcinoma and hepatocellular carcinoma, for which therapeutic peptide vaccination with viral-encoding peptides have been developed and tested with promising results (5-7). Furthermore, neoantigens arising as a result of DNA mutations in cancer cells offer ideal targets, as T cells have not been centrally tolerized against these antigens. Additionally, some less immunogenic peptides with WT amino acid sequences - such as differentiation antigens, overexpressed antigens, and cancer/testis antigens - are currently under investigation (8).

\section{Related Commentary: p. 480}

Conflict of interest: The authors have declared that no conflict of interest exists. Submitted: July 10, 2015; Accepted: November 12, 2015.

Reference information: J Clin Invest. 2016;126(2):784-794. doi:10.1172/JCI83671.
Now that $\mathrm{T}$ cell-based immunotherapies meet clinical success, the emergence of immune-escape mechanisms of cancers becomes an increasing problem. The selection pressure of immune-mediated therapies on cancer lesions will most likely lead to immune-refractory phenotypes, such as loss of MHC-I antigen presentation. Case studies of immunotherapy in melanoma patients already demonstrated progression of cancer lesions with very low expression of HLA class I, whereas cancer lesions with normal expression of HLA class I in the same patient did regress $(9,10)$. Human cancers frequently lose surface expression of HLA class I molecules, and this type of escape constitutes a hurdle for T cell-based therapy. Indeed, these defects correlate with poorer prognosis and metastatic spread, supporting the importance of immune surveillance by tumor-specific $\mathrm{CD} 8^{+} \mathrm{T}$ cells $(10$, 11). HLA class I defects can be caused by structural aberrations or by silencing of gene expression and often involve components of the processing machinery. Interestingly, very similar escape strategies have been described for persistent viruses from the herpes family due to dedicated viral proteins perturbing the function of processing components, such as the peptide transporter associated with antigen processing (TAP) (12).

We previously identified $\mathrm{CD} 8^{+} \mathrm{T}$ cells that specifically recognize TAP-deficient tumor cells, which were otherwise resistant to antitumor T cells targeting conventional tumor antigens (1316). The recognition of these MHC-I ${ }^{\text {lo }}$ tumors depends on TCR/ MHC-I interactions and targets a novel class of antigens, called TEIPP (T cell epitopes associated with impaired peptide processing). TEIPP peptides derive from housekeeping proteins that are ubiquitously expressed but only emerge in complex with MHC-I 
Table 1. Specification of the TCR of the LnB5 T cell clone

\begin{tabular}{|c|c|c|}
\hline & TCR $\alpha$ chain & TCR $\beta$ chain \\
\hline$V(D)$ J region ${ }^{A}$ & TRAV9N-3*01 J15*01 & TRBV13-2*01 D1*01 J1-4*02 \\
\hline \multicolumn{3}{|l|}{ CDR3 region } \\
\hline Amino acid sequence & CAVSPYQGGRALIF & CASGEWDNANERLFF \\
\hline$V(D)$ J region & $\begin{array}{l}\text { ATGCTCCTGGCGCTCCTCCCAGTGCTGGGGATACACTTTCTCCTGAGAGAT- } \\
\text { GCCCAAGCTCAGTCAGTCACGCAGCCCGATGCTCGCGTCACTGTCTCTGAAG- } \\
\text { GAGCCTCTCTGCAGCTGAGATGCAAGTATTCCTACTTTGGGACACCTTATCT- } \\
\text { GTTCTGGTATGTCCAGTACCCGCGGCAGGGGCTGCAGCTGCTCCTCAAGTAC- } \\
\text { TATCCAGGAGACCCAGTGGTTCAAGGAGTGAATGGCTTTGAGGCTGAGTTCAG- } \\
\text { CAAGAGTAACTCTTCCTTCCACCTGCGGAAAGCCTCTGTGCACTGGAGCGACT- } \\
\text { GGGCTGTGTACTTCTGTGCTGTGAGCCCCTACCAGGGAGGCAGAGCTCTGA- } \\
\text { TATTTGGAACAGGAACCACGGTATCAGTCAGCCCCA }\end{array}$ & $\begin{array}{l}\text { ATGGGCTCCAGGCTCTTCTTCGTGCTCTCCAGTCTCCTGTGTTCAAAACA- } \\
\text { CATGGAGGCTGCAGTCACCCAAAGCCCAAGAAACAAGGTGGCAGTAACAG- } \\
\text { GAGGAAAGGTGACATTGAGCTGTAATCAGACTAATAACCACAACAA- } \\
\text { CATGTACTGGTATCGGCAGGACACGGGGCATGGGCTCAGGCTGATCCAT- } \\
\text { TATTCATATGGTGCTGGCAGCACTGAGAAAGGAGATATCCCTGATGGATA- } \\
\text { CAAGGCCTCCAGACCAAGCCAAGAGAACTTCTCCCTCATTCTGGAGTTGGC- } \\
\text { TACCCCCTCTCAGACATCAGTGTACTTCTGTGCCAGCGGTGAGTGGGACAAT- } \\
\text { GCCAACGAAAGATTATTTTTCGGTCATGGAACCAAGCTGTCTGTCCTGG }\end{array}$ \\
\hline
\end{tabular}

ANomenclature according to ImMunoGeneTics.

on the cell surface in the absence of the peptide transporter TAP. The prototypic TEIPP antigen is derived from the TRH4 protein, a ceramide synthase spanning the ER membrane. We have demonstrated that processing of the TRH4 epitope is mediated by the signal peptide peptidase enzyme within the lipid bilayer, independently of proteasome and TAP (13). Although the TRH4 protein is ubiquitously expressed and the MHC-I-restricted TRH4-derived peptide is liberated in all cells, only TAP-deficient cells present the TRH4 peptide/MHC-I at the cell surface, most likely due to peptide competition in the ER (14). As such, TEIPP peptides are true nonmutated self-antigens.

In the present study, we investigated the generation of the TEIPP T cell repertoire. T cell receptor (TCR) transgenic animals were constructed harboring rearranged receptors recognizing the TRH4/D ${ }^{b}$ complex (named LnB5). We observed efficient selection of this TCR in the thymus, a strong CD8 skewing of the T cells, and high quantities of naive phenotype in the periphery. The $\mathrm{T}$ cells were readily activated by peptide vaccination and killed target cells efficiently. Backcrossing the TCR transgene onto a TAP1-deficient background revealed a strong deletion in the thymus, as well as hampered, Helios ${ }^{+}$cells in the periphery, underlining the efficient selection of the T cell repertoire in WT mice. Finally, we show that LnB5 tg cells control tumor outgrowth of the TAP2-deficient lymphoma cell line RMA-S. Together, our data demonstrate that TEIPP T cells are not blunted via peripheral or central tolerance and can be exploited for the fight against cancers with defects in the antigen processing machinery.

\section{Results}

TCR determines the selection of TEIPP-specific CD $8^{+} T$ cells. We previously isolated a $\mathrm{CD}^{+} \mathrm{T}$ cell clone (LnB5) that specifically recognizes a TEIPP antigen from TRH4, a housekeeping ceramide synthase, presented by the MHC-I molecule $\mathrm{D}^{\mathrm{b}}$ on TAP-deficient tumor cells. We demonstrated that this TRH4 peptide represents a TEIPP peptide in that it is processed in a proteasome- and TAP-independent manner and is displayed by TAP-deficient cells $(13,14,16)$. To study the generation from the thymus and the behavior in the periphery of TEIPP T cells, we constructed
TCR transgenic mice (called hereafter LnB5 tg mice) bearing the rearranged $\alpha \beta$ receptors of the TRH4/D $\mathrm{D}^{\mathrm{b}}$-reactive clone LnB5. First, the TCR $\alpha \beta$ were cloned, sequenced (Table 1 ) and expressed in C57BL/6 splenocytes in order to validate functional production and reactivity of the receptors. After transduction, cell surface expression of the LnB5 TCR was detected by flow cytometry using the $\mathrm{V} \alpha 3$ and $V \beta 8$ antibodies (Figure 1A). Since this $\mathrm{V} \alpha 3-\mathrm{V} \beta 8$ combination is rare in the endogenous population of CD8 $\mathrm{T}$ cells of C57BL/ 6 mice, retroviral introduction of TCR $\alpha \beta$ were readily detectable. Stimulation of the transduced cells with the TRH4 peptide resulted in IFN $\gamma$ production, showing that the cloned TCR conferred recognition of this TEIPP peptide (Figure 1B). No IFN $\gamma$ was detected when TCR transduced cells were stimulated with a control peptide. LnB5 tg mice were then generated using an improved human CD2 promoter and enhancer construct to enforce expression in early thymocytes. In LnB5 tg mice, virtually all (>90\%) peripheral $\mathrm{CD}^{+} \mathrm{T}$ cells expressed the transgenic TCR (Figure 1C), showing efficient generation of transgenic $\mathrm{CD}^{+} \mathrm{T}$ cells. Hardly any $\mathrm{CD} 4^{+} \mathrm{T}$ cells were double positive (DP) for transgenic TCR $\alpha$ and TCR $\beta$, suggesting strong CD8 coreceptor dependence of this TCR. Indeed, a strong skewing toward circulating $\mathrm{CD}^{+} \mathrm{T}$ cells was found, shifting the CD8/CD4 ratio more than 10-fold (Figure 1, D and E), similar to what is observed in other transgenic mice models that express MHC-I-restricted TCR $(17,18)$. Importantly, CD8 ${ }^{+} \mathrm{T}$ cells clearly displayed a naive phenotype, comparable to $\mathrm{CD} 8^{+} \mathrm{T}$ cells from the endogenous repertoire of WT C57BL/6 mice (Figure 1F). Furthermore, no expression was detected on naive LnB5 cells of several analyzed NK receptors (NK1.1, Ly49H, NKG2A, CD94, CD49b, and NKG2D), implying that the generation of TEIPP T cells was determined by the TCR and did not depend on these NK receptors, which are closely associated with immune recognition of MHC-I $\mathrm{I}^{\mathrm{lo}}$ target cells (Figure $1 G$ ). In conclusion, the LnB5 TCR is sufficient to confer TEIPP reactivity and governs the generation of TEIPP CD8 ${ }^{+} \mathrm{T}$ cells.

Thymus education on Tap1/-- background largely deletes LnB5 $T$ cells and severely hampers their function. The skewing toward the $\mathrm{CD} 8^{+} \mathrm{T}$ cell lineage observed in LnB5 tg mice suggested a 

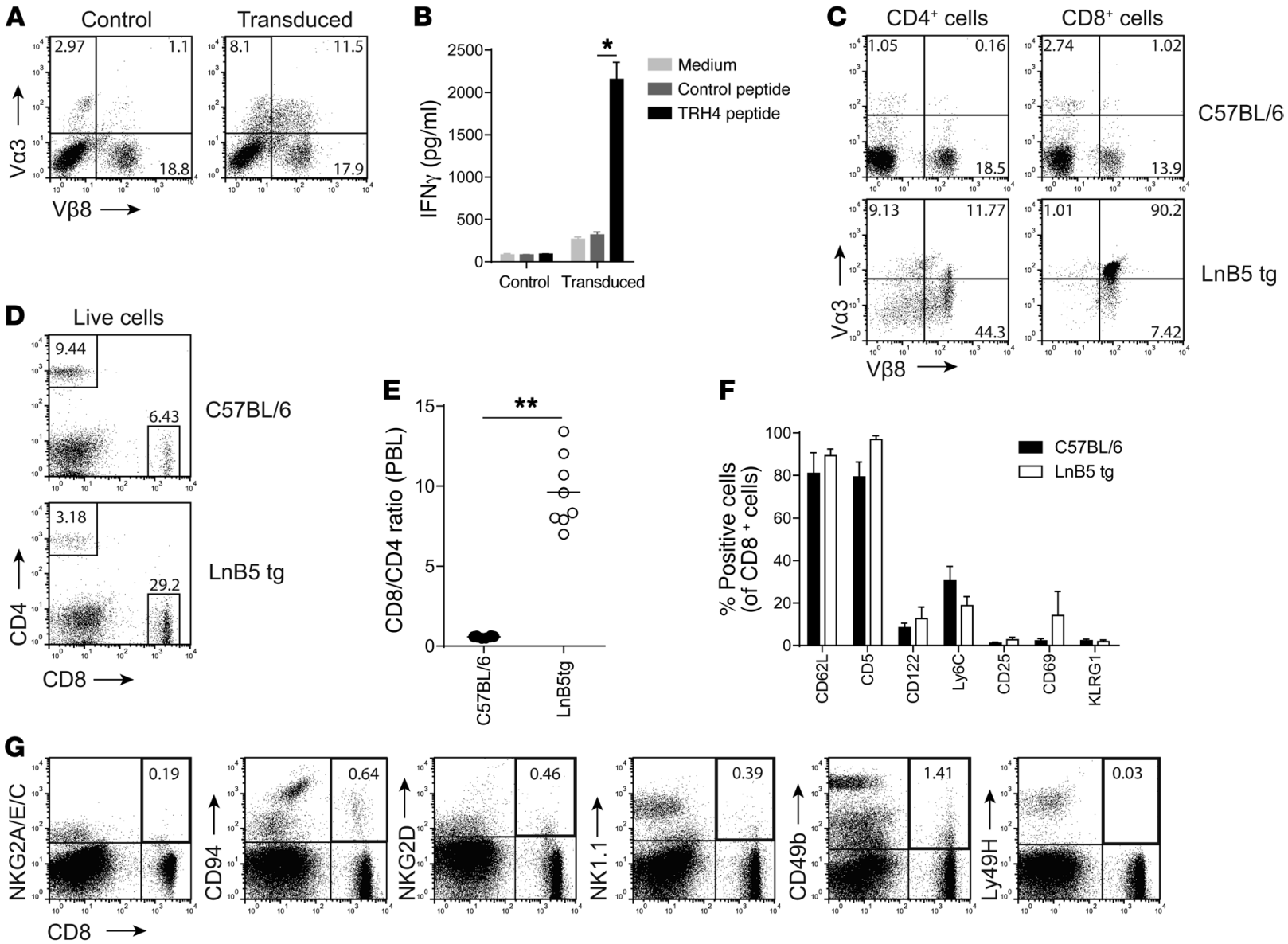

$\mathbf{F}$
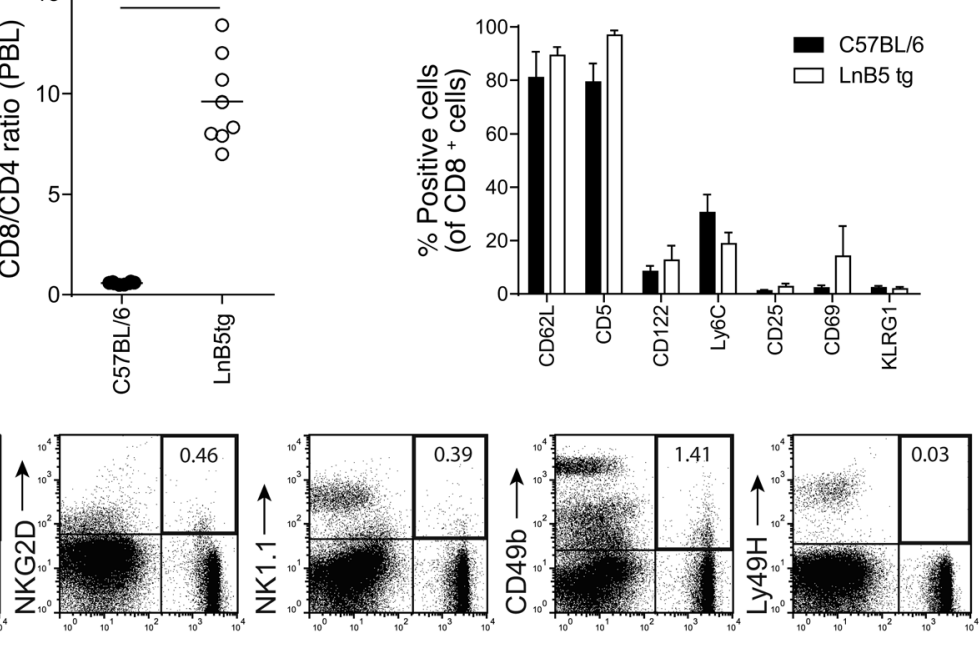

Figure 1. TEIPP TCRs confer TEIPP reactivity. (A) Splenocytes were transduced with viral vectors encoding the cloned TCR $\alpha$ and TCR $\beta$ chain of the LnB5 clone or with a control virus. Transduced cells were analyzed by flow cytometry for the presence of the transgenic TCR. (B) Transduced splenocytes were stimulated overnight with the TRH4 peptide or a control peptide, and IFN $\gamma$ production was analyzed by ELISA. Mean \pm SD are plotted of 2 independent experiments. (C and D) LnB5 tg mice were generated (LnB5 tg), and blood samples of WT (C57BL/6) and LnB5 tg mice were analyzed by flow cytometry. (E) Ratios of CD8+ and CD4+ T cells in blood of individual WT (C57BL/6) or LnB5 tg mice. Data from 4 independent experiments; total of 8 mice per phenotype. (F) Expression of activation markers on CD8+ T cells in C57BL/6 or LnB5 tg mice. Mean \pm SEM from data pooled from 4 independent experiments is shown, with 8 mice per group. (G) NK cell marker expression, gated on live cells, representative of 3 independent experiments. Student $t$ test, ${ }^{*} P<0.05,{ }^{*} P<0.001$.

normal thymic selection in these mice, although we previously demonstrated that epithelial cells in the thymus express the Trh 4 gene and also present peptide/ $\mathrm{D}^{\mathrm{b}}$ complexes when deficient for TAP function (14). As expected, a clear $\mathrm{CD}^{+}$single positive (SP) population was observed in thymi of LnB5 tg mice on a $\mathrm{C} 57 \mathrm{BL} / 6$ background ( $\mathrm{LnB} 5^{\mathrm{WT}}$ ) and a reduced DP population, most likely due to the efficient selection of $\mathrm{CD}^{+} \mathrm{T}$ cells (Figure 2A). To study the thymic selection on an antigen-positive background, LnB5 tg mice were crossed on a TAP1-deficient background (LnB5 $\mathrm{Tap1}^{-/-}$). Thymi of LnB5 $\mathrm{Tap1}^{-/-}$mice lacked a distinct mature $\mathrm{CD}^{+}$SP population; instead, a small subset of thymocytes with intermediate CD8 and low CD4 expression was found (Figure 2A). The DP population was severely reduced, suggesting a fast deletion of TCR $\alpha \beta^{+}$thymocytes. Moreover, the overall cellularity of the thymus was dramatically decreased (Figure 2B), again suggesting negative selection. When absolute counts of thymocytes were plotted for each developmental stage (double negative [DN], DP, CD $4^{+} \mathrm{SP}$ and $\mathrm{CD} 8^{+} \mathrm{SP}$ ), clear differences were observed between LnB5 $\mathrm{Tap1}^{-/-}$and nontransgenic
Tap1 $1^{-/-}$mice, indicating that the aberrations were not the result of a lack of stimulation due to low MHC-I levels but were related to TRH4 antigen presentation (Figure 2C). CD8 ${ }^{+} \mathrm{SP}$ cells in LnB5 ${ }^{\mathrm{WT}}$ and LnB5 Tap1 ${ }^{-/-}$mice had comparable levels of the TCR $\beta$ chain (VB8), which was driven by the heterologous hCD2 promoter (Figure 2D). However, CD8 ${ }^{+} \mathrm{SP}$ cells in LnB5 $\mathrm{Tap1}^{-/-}$mice had reduced CD8 and TRH4/ $\mathrm{D}^{\mathrm{b}}$-tetramer staining levels, indicative of reduced TCR avidity (19). Additionally, cells in these mice had an increased expression of the transcription factor Helios, a member of the Ikaros family of transcription factors, associated with self-reactive $\mathrm{T}$ cells $(20,21)$. The increased Helios expression could not be attributed to the Tap1 $1^{-/-}$background per se, as no difference in Helios expression was observed in CD8 ${ }^{+}$ SP cells in normal C57BL/6 or Tap1 $1^{-/-}$mice (Supplemental Figure 1A; supplemental material available online with this article; doi:10.1172/JCI83671DS1). The major deletions in thymic cellularity, especially of the DP and $\mathrm{CD}^{+} \mathrm{SP}$ and the reduced TCR avidity of the latter populations, suggested severe negative deletion in LnB5 $\operatorname{tg}$ mice on a Tap1/-- background. 
A

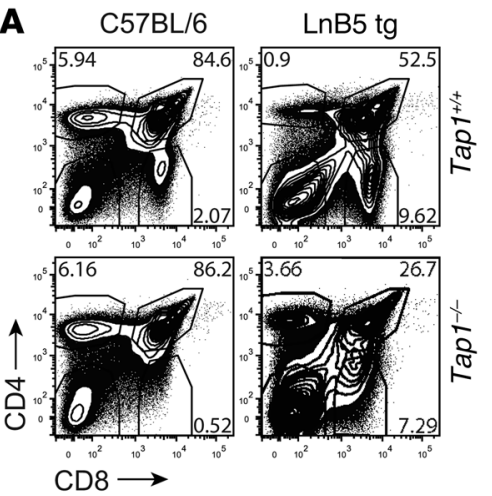

D
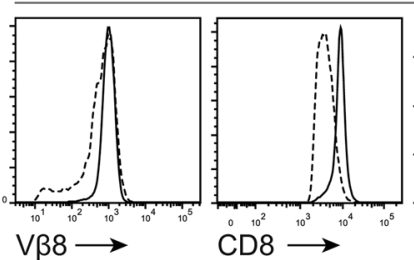

$\mathrm{CD}^{+} \mathrm{SP}$ cells
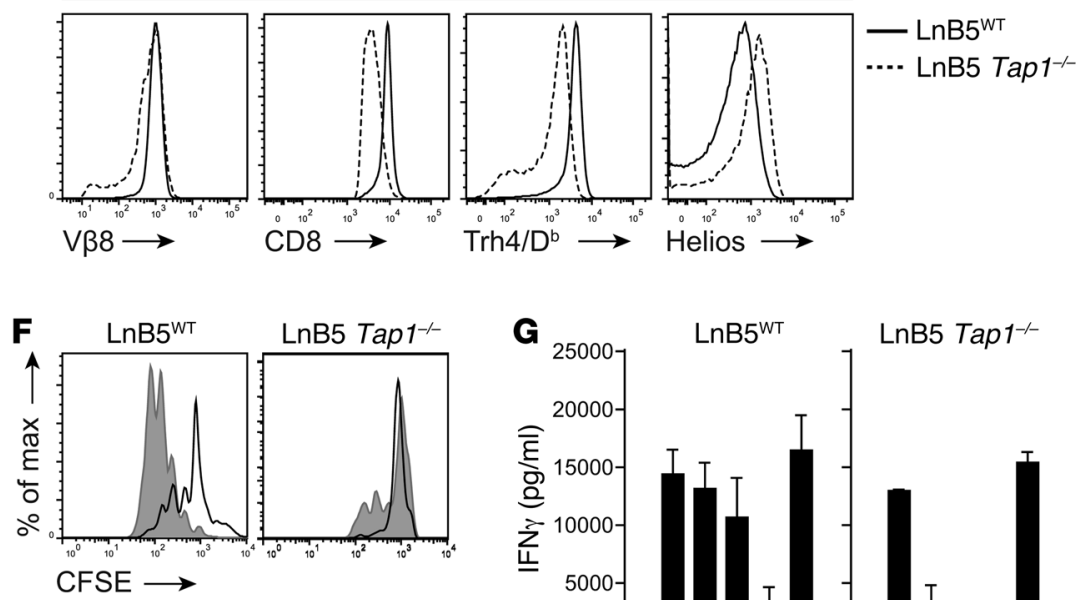

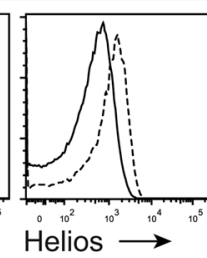

B
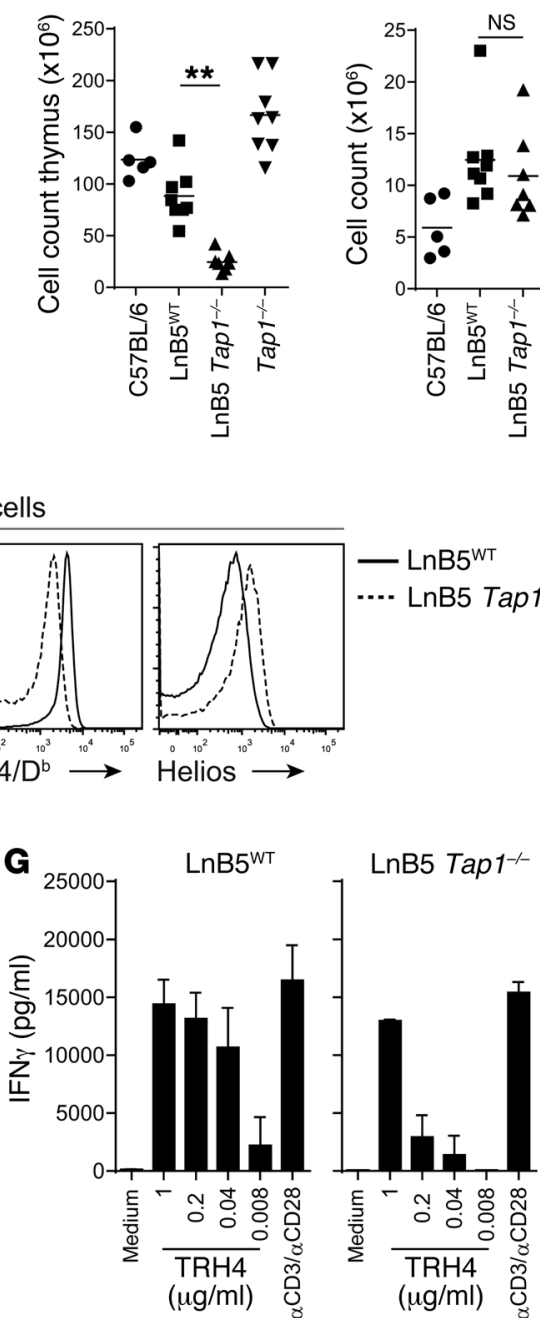
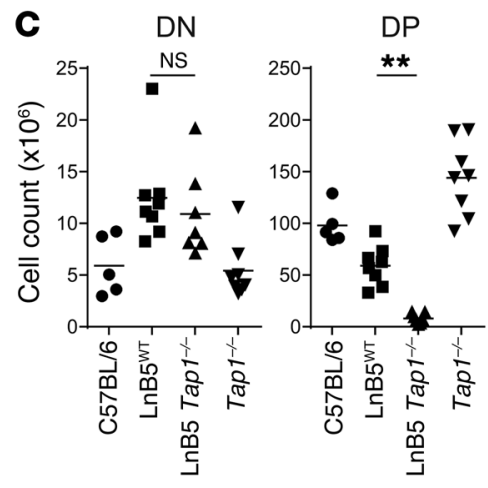

CD4 SP

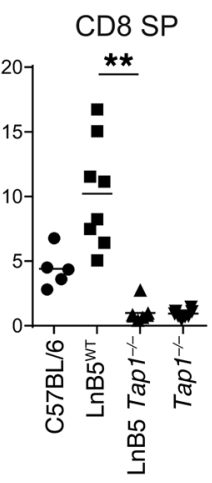

E

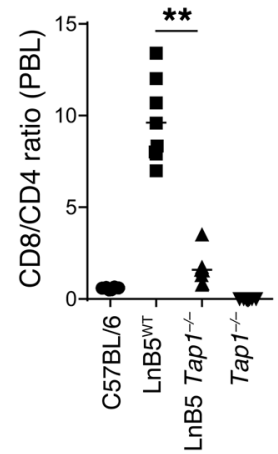

Figure 2. LnB5 tg T cells are efficiently selected on a WT background. Thymic selection of LnB5 tg T cells was studied by crossing LnB5 tg mice to a Tap1 $1^{-/-}$-deficient background. (A) Representative flow cytometric analysis of thymi from C57BL/6, Tap $1^{-/-}$, Tap $7^{+/+}$, and LnB5 Tap ${ }^{-/-}$mice. (B and C) Cell counts of total thymus and of separate developmental stages. Data pooled from 4 independent experiments; 5-8 mice per group. (D) Flow cytometric analysis of $\mathrm{CD8} 8^{+} \mathrm{SP}$ cells in thymi of $\mathrm{Tap1}^{1^{+/}}$or $\mathrm{LnB5} \mathrm{Tap1}^{-/-}$mice. Histograms are representative for $6-9$ mice per group. (E) CD8/CD4 ratio in blood of mice; 5-8 mice per group. (F and $\mathbf{G}$ ) CD8 ${ }^{+} \mathrm{T}$ cells were isolated from spleen and LN of transgenic mice, labeled with CFSE and incubated in a 3-day in vitro proliferation assay, and stimulated for 3 days with TRH4 peptide (filled histogram) or medium (open histogram). Data are representative of 3 experiments, with different mice. (C) IFN $\gamma$ was measured in supernatant of in vitro proliferation assays. Data represent means and SD of triplicates from 1 of 3 independent experiments. Student $t$ test, ${ }^{* *} P<0.001$.

Next, we analyzed the peripheral phenotype and function of these TEIPP $\mathrm{T}$ cells. The strong skewing toward the CD8 ${ }^{+}$ $\mathrm{T}$ cell lineage, as observed in the periphery of mice on the WT background, was completely lost in LnB5 Tap1 ${ }^{-/}$mice (Figure $2 \mathrm{E}$ and Supplemental Figure 1B). Very low frequencies of $\mathrm{CD}^{+} \mathrm{T}$ cells, but also $\mathrm{CD}^{+} \mathrm{T}$ cells, were observed in $\mathrm{LnB} 5 \mathrm{Tap1}^{-/-}$mice, and CD8/CD4 ratios of LnB5 Tap1 $1^{--}$mice approached those of $\mathrm{C} 57 \mathrm{BL} / 6$ mice (Figure 2E). All the residual $\mathrm{CD} 8^{+} \mathrm{T}$ cells in the blood of LnB5 Tap1 ${ }^{-1}$ mice demonstrated an antigen-experienced phenotype, as witnessed by expression of Ly6C and CD122 (Supplemental Figure 1C). In addition, the peripheral $\mathrm{CD}^{+} \mathrm{T}$ cells expressed high levels of the transcription factor Helios (Supplemental Figure 1D). The Helios ${ }^{+} \mathrm{CD}^{+} \mathrm{T}$ cells in LnB5 $\mathrm{Tap1}^{-/}$mice did not express FoxP3 (data not shown), but we speculate that Helios expression is a result of the high acti- vation status of LnB5 T cells in this TRH4/ $\mathrm{D}^{\mathrm{b}}$-presenting environment. In concordance with cells in the thymus, peripheral $\mathrm{CD}^{+} \mathrm{T}$ cells displayed decreased levels of $\mathrm{CD} 8 \alpha$ and TRH4 $4 \mathrm{D}^{\mathrm{b}}$ tetramers (Supplemental Figure 1D).

To examine the functionality of the $\mathrm{CD} 8^{+} \mathrm{T}$ cells that were educated on a Tap1 $1^{-/}$background, they were isolated from spleen and lymph nodes and used in an in vitro proliferation assay with or without TRH4 peptide stimulation. All $\mathrm{CD}^{+} \mathrm{T}$ cells from $\mathrm{LnB} 5^{\mathrm{WT}}$ mice underwent proliferation upon TRH4 peptide encounter and produced IFN $\gamma$ (Figure 2, F and G). In contrast, a very small percentage of $\mathrm{CD}^{+} \mathrm{T}$ cells from LnB5 Tap1 $1^{-/}$mice proliferated when stimulated with the cognate peptide in vitro, and much lower quantities of IFN $\gamma$ were produced. From these data, we concluded that the hampered function of $\mathrm{CD} 8^{+} \mathrm{T}$ cells raised in Tap1 $1^{--}$mice was related to thymic selection on an antigen-positive back- 
A
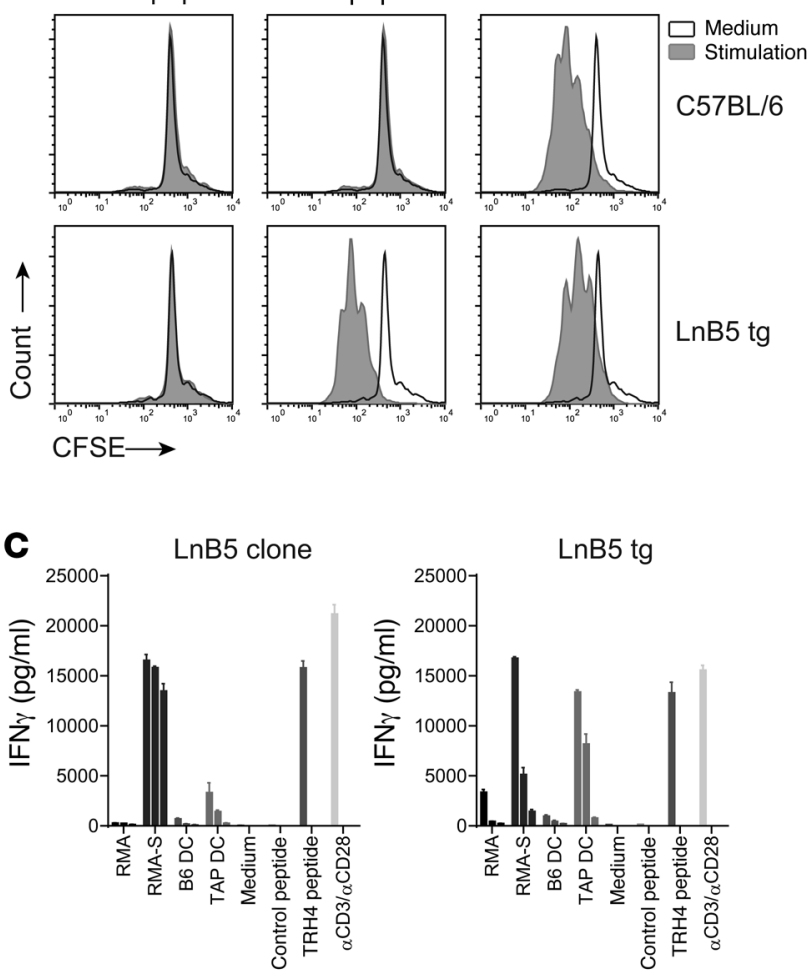

LnB5 tg

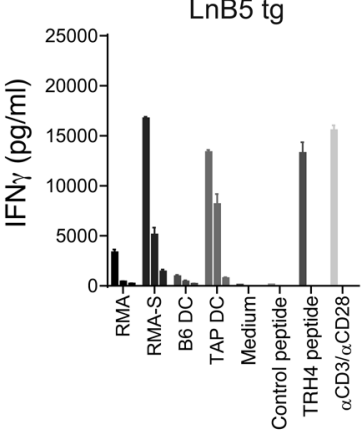

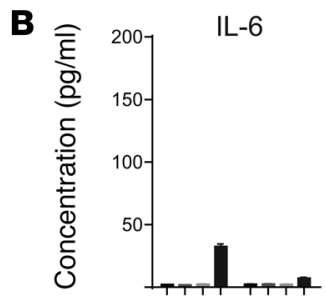
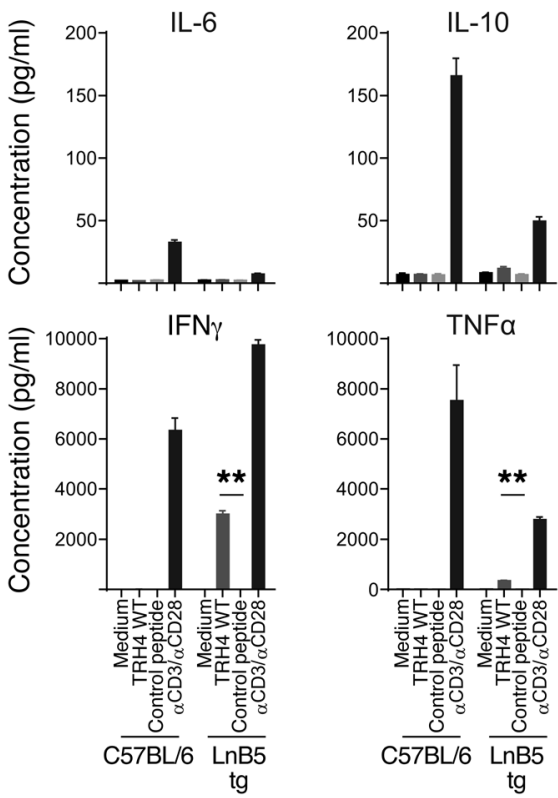

Figure 3. Sensitive and selective activation of naive TEIPP T cells. TEIPP T cell functionality was examined; CD8 ${ }^{+}$T cells were isolated, labeled with CFSE, and incubated in a 3-day proliferation assay. (A) Proliferation after stimulation with peptide $(1 \mu \mathrm{g} / \mathrm{ml})$ or $\alpha \mathrm{CD} 3 / \alpha \mathrm{CD} 28 \mathrm{stimulation}$. Filled histogram, stimulated; open histogram, medium control; representative of 3 independent experiments (B) Supernatant of culture wells was analyzed for cytokine release by cytokine bead array (CBA). Data shown from 1 of 2 independent experiment, as means and SD of triplicate wells. (C) Activated LnB5 tg T cells were tested for recognition of a panel of target cells. IFN $\gamma$ production after overnight stimulation was measured by ELISA. Means and SD of triplicate wells from 1 of 3 independent experiments is shown. Student $t$ test, ${ }^{* *} P<0.001$.

ground. Importantly, all these observed characteristics of negative selection of LnB5 T cells on Tap1 $1^{-/}$background corroborated our conclusion that the TEIPP $\mathrm{T}$ cell repertoire is not hampered on normal WT background.

The preferential recognition of TAP-deficient target cells is determined by TEIPP TCR. We next explored the functional properties of TEIPP-specific LnB5 tg T cells ex vivo in more detail. To this end, naive $\mathrm{CD} 8^{+} \mathrm{T}$ cells were purified from spleen and lymph nodes of LnB5 tg, labeled with CFSE, and cultured in the presence of various stimuli. After 3 days, proliferation and cytokine production were analyzed (Figure 3, A and B). Upon stimulation with agonistic $\alpha \mathrm{CD} 3 / \alpha \mathrm{CD} 28$ antibodies, TEIPP $\mathrm{T}$ cells strongly proliferated to a comparable extent as $\mathrm{CD} 8^{+} \mathrm{T}$ cells from WT C57BL/6 mice (Figure $3 \mathrm{~A})$. In addition, cells produced both IFN $\gamma$ and TNF $\alpha$ at high levels (Figure 3B). Stimulation with cognate TRH4 peptide also resulted in proliferation and IF $\gamma \gamma$ production, whereas this was not detected when the T cells were incubated with a control peptide. Production of TNF $\alpha$ was lower but clearly detectable. Next, the IFN $\gamma$ response of in vitro primed LnB5 tg T cells was measured to a panel of natural targets and compared with the original TEIPP $\mathrm{T}$ cell clone LnB5 (Figure 3C). The TAP2-deficient lymphoma RMA-S, as well as DCs from Tap1 ${ }^{-/}$mice, stimulated LnB5 tg T cells much stronger than their TAP-proficient counterparts, similar to the original T cell clone. Together, our data reveal that both TEIPP reactivity and TEIPP specificity are determined by the TCR.
TEIPP T cells remain ignorant after transfer in WT mice, even in inflammatory conditions. The observations on the in vitro responses of $\mathrm{LnB} 5 \mathrm{tg} \mathrm{T}$ cells incited us to investigate the in vivo behavior of these TEIPP CD $8^{+} \mathrm{T}$ cells in settings of display of the TRH4 self-antigen. Naive CFSE-labeled LnB5 tg $\mathrm{T}$ cells were transferred into WT C57BL/6 mice and Tap1 ${ }^{-/-}$mice, both expressing comparable levels of the Trh 4 gene in their organs (Figure $4 \mathrm{~A}$ and ref. 14). Three days after $\mathrm{T}$ cell transfer, the LnB5 $\mathrm{T}$ cells had undergone several cycles of proliferation in Tap1-- mice, but the cells in the WT mice did not proliferate (Figure 4B). Interestingly, the proliferating $\mathrm{T}$ cells in TAP-deficient mice did not accumulate and did not display CD62L downregulation, strongly suggesting that they underwent abortive proliferation, a form of $\mathrm{T}$ cell activation leading to functional tolerance previously described to occur due to the absence of inflammatory signals $(22,23)$. To examine whether the lack of activation and accumulation of LnB5 cells in Tap1-/- mice was due to this process, mice were given agonistic $\alpha \mathrm{CD} 40$ antibody, which potently activates antigen-presenting cells (24). In $\alpha \mathrm{CD} 40$-treated mice, LnB5 tg T cells indeed underwent a larger amount of division cycles, strongly accumulated in the hosts and downregulated CD62L (Figure 4, B and C). Thus, the addition of agonistic $\alpha$ CD 40 antibody led to proper $\mathrm{T}$ cell activation. Importantly, $\mathrm{T}$ cells in WT animals did not show any sign of antigen stimulation, even though the TRH4 protein is present in these animals and strong inflammatory signals were provided (Figure 3, B and C). To exclude that 
A

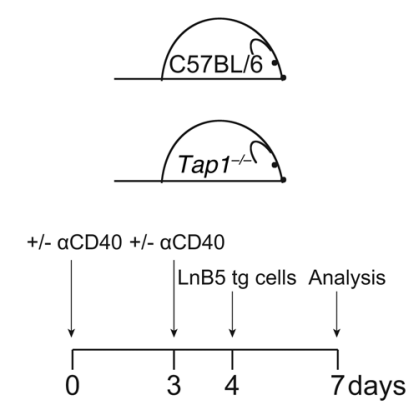

B
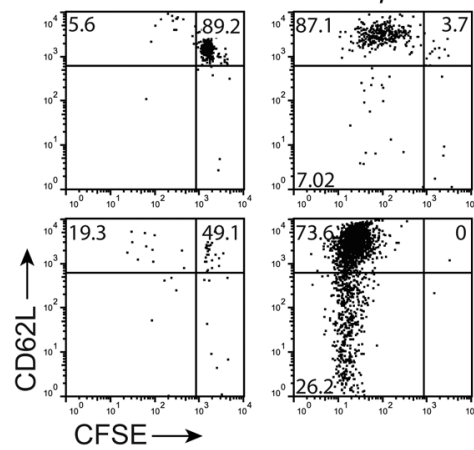

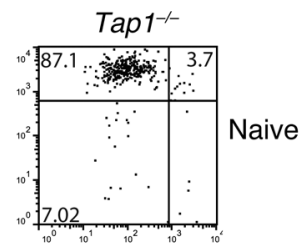

$\alpha \mathrm{CD} 40$
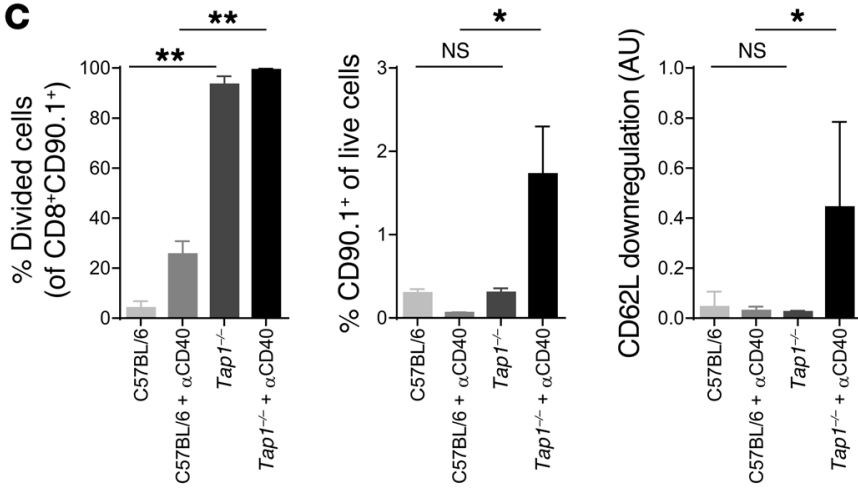

D
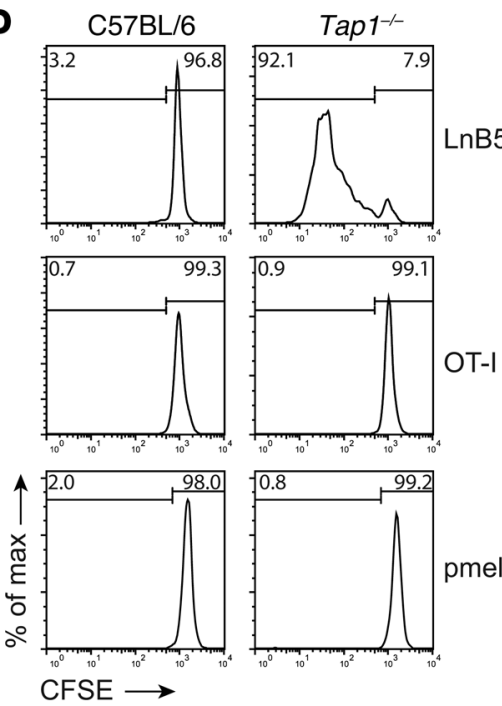

E

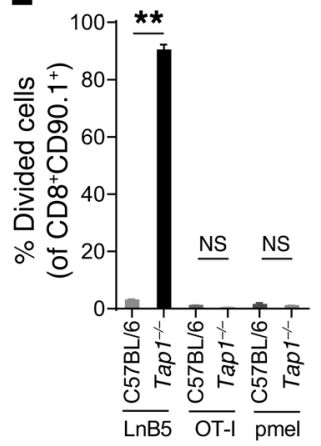

TEIPP T cells proliferated in $\mathrm{Tap1}^{-/}$mice as a result of homeostatic proliferation, we transferred 2 control TCR tg T cells, one with foreign- and one with self-specificity (OVA and gp100, respectively). No proliferation and no activation of the OVA-specific OT-I and the gp100-specific pmel $\mathrm{T}$ cells was observed when transferred in Tap1-- mice (Figure 4, D and E). This indicates that proliferation of LnB5 tg T cells in Tap1 ${ }^{-}-$mice was antigen driven and not the result of homeostatic proliferation. Importantly, these data also demonstrate that TEIPP T cells remain ignorant in WT mice, even in the presence of inflammatory signals.

Efficient cross-priming of TEIPP T cells by vaccination with a synthetic long peptide. As TAP-deficient antigen-presenting cells efficiently primed LnB5 $\mathrm{tg} \mathrm{T}$ cells in Tap1-- mice and endogenous TRH4
Figure 4. TEIPP $T$ cells remain ignorant after adoptive transfer to WT mice. CFSE-labeled LnB5 tg cells were transferred in C57BL/6 or Tap1 $1^{-1-}$ mice; proliferation, and activation of cells was measured in blood of recipient mice. (A) Experimental setup. (B) Flow cytometric analysis of blood 3 days after $T$ cell transfer. Gate on $\mathrm{LnB} 5 \mathrm{tg} T$ cells (CD90.1+CD8+ T cells). (C) Quantification of LnB5 tg cells in blood of recipient mice. CD62L downregulation was expressed as arbitrary units (AU: \%CD90.1 of live $\times \%$ CD62 $L^{10}$ of divided CD90.1+ cells). Data are shown from 2 independent experiments as mean with \pm SEM from 2-3 mice per group. (D and E) CFSE-labeled LnB5 tg, pmel tg (gp100/D specific), or OT-I tg (OVA/ $/ K^{\mathrm{b}}$ specific) T cells were transferred in C57BL/6 or Tap1 ${ }^{-1-}$ mice, and blood was analyzed 3 days after transfer. Data shown as means with \pm SEM of 2-3 mice per group. Student $t$ test, ${ }^{*} P<0.05,{ }^{*} P<0.001$.

proteins in WT mice apparently failed to cross-prime TEIPP $T$ cells, we examined the capability of vaccination approaches to induce TEIPP $\mathrm{T}$ cell responses in a WT background in which all antigen-presenting cells are TAP proficient. First, we investigated whether TAP-proficient DCs processed and presented longer versions of synthetic peptides comprising TEIPP epitopes. DCs were incubated for 5 hours with HPLC-purified 21-mer long TRH4 peptide and, after extensive washing, offered to LnB5 T cells. These peptide-loaded DCs were surprisingly efficient in stimulating the $\mathrm{T}$ cells, indicating that TAP-proficient DCs are capable of cross-presenting exogenously loaded long TEIPP peptides (Figure 5A). Next, WT mice were vaccinated with the purified long TRH4 peptide and the response of transferred naive $\operatorname{LnB} 5$ tg $\mathrm{T}$ cells was measured over time (Figure 5B). After the second vaccination, an extensive expansion of the congenically marked $\mathrm{T}$ cells was observed, accompanied by proper activation (Figure 5C) and IFN $\gamma$ production (Figure 5D). The strength and magnitude of the response were rather similar to those achieved with vaccination using the minimal short peptide, demonstrating that TAP-proficient host DCs in WT mice are impeccably capable to cross-prime TEIPP T cells.

To measure killing capacities of activated TEIPP $\mathrm{T}$ cells, an in vivo cytotoxicity assay was performed. Vaccinated animals were challenged with differentially CFSE-labeled splenocytes pulsed with either short TRH4 peptide or control peptide. More than $80 \%$ of the TRH4-pulsed target cells were killed in vaccinated mice (Figure 5, E and F). Of note, vaccination did not induce a cytolytic $\mathrm{T}$ cell response from the endogenous CD8 T cell repertoire, since transfer of naive LnB5 tg T cells was necessary to observe killing. The precursor frequencies of TRH $4 / \mathrm{D}^{\mathrm{b}}$ reactive $\mathrm{T}$ cells is most likely too low for this type of assay, as previous findings already revealed that this epitope is subdominant in this model (25). Next, splenocytes from C57BL/6 and Tap1 ${ }^{-/}$mice were used as target populations (Figure $5, \mathrm{G}$ and $\mathrm{H}$ ). Approximately $30 \%$ of TAP-deficient splenocytes were selectively killed. These experiments were performed in the absence of NK cells to prevent NK-mediated killing of TAP-deficient and MHC-I $\mathrm{I}^{\mathrm{lo}}$ targets. Taken 
A
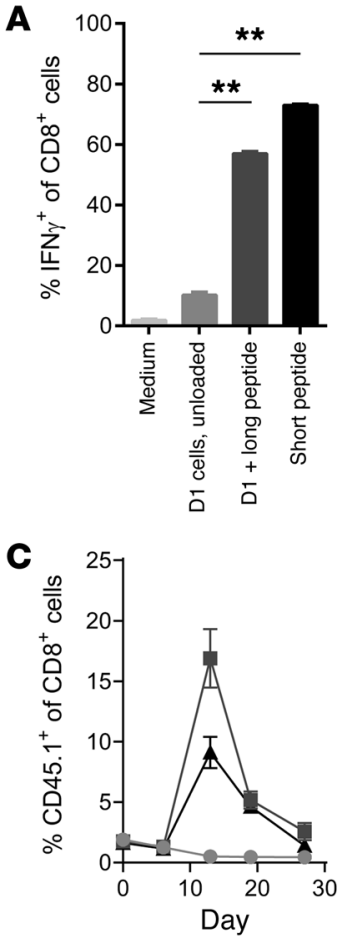

E

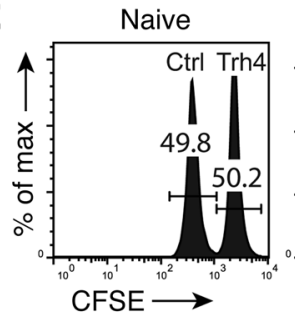

$\mathbf{F}$

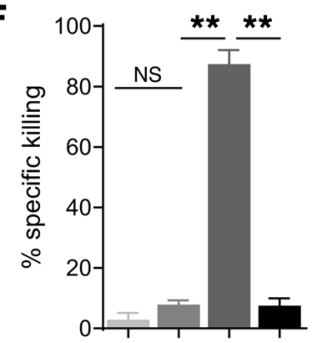

LnB5 tg cells - +++

Vaccination -
B

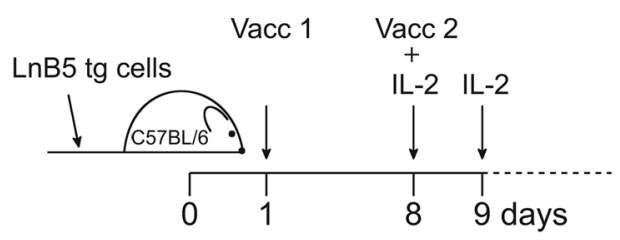

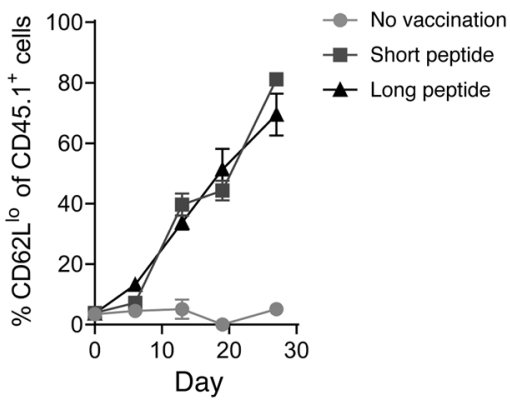

LnB5 tg cells

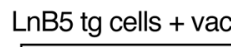

Vaccination only
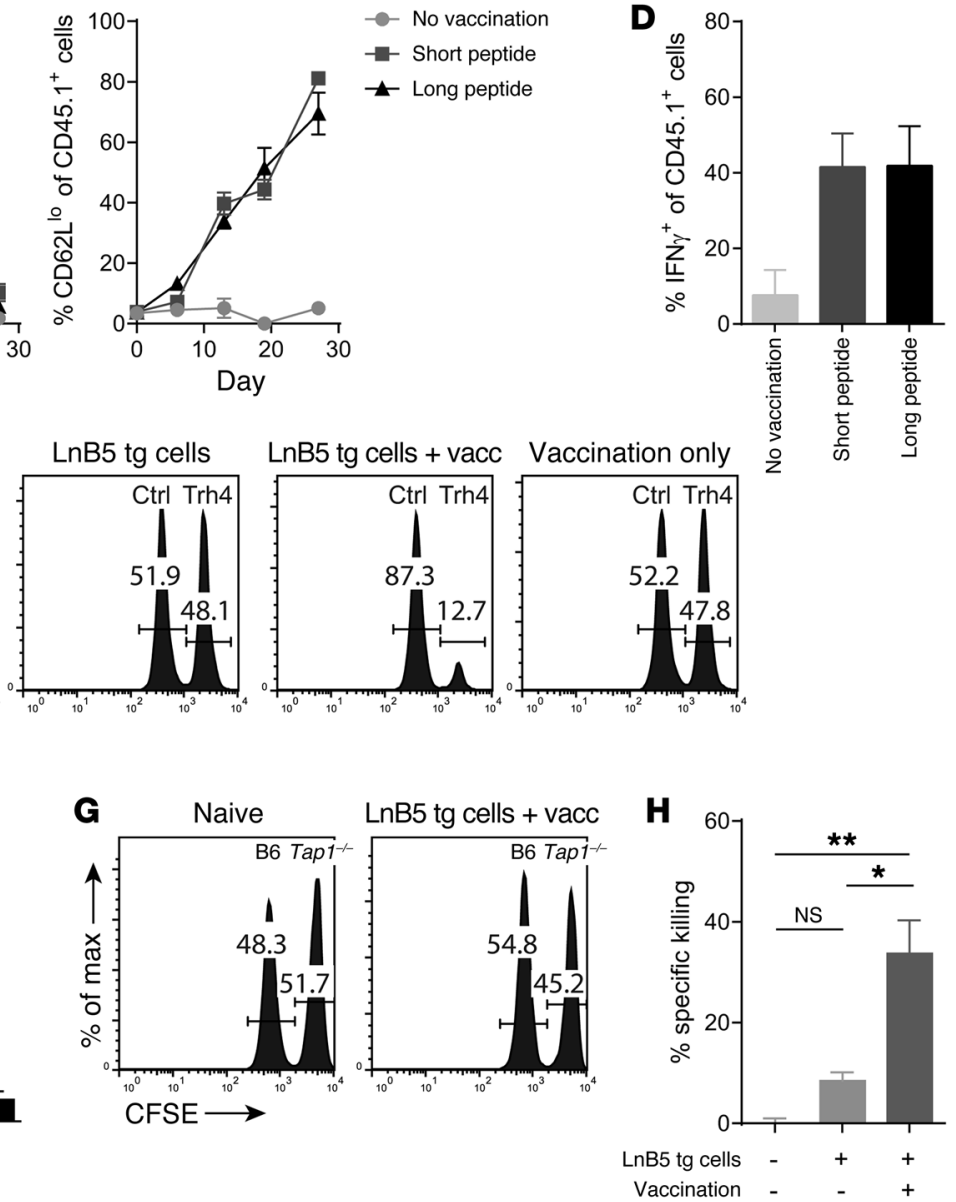

Figure 5. Peptide vaccination leads to cross-presented antigen and strong activation of TEIPP T cells. (A) DCs were loaded for 5 hours with purified 20-mer long TRH4 peptide. Cells were washed and cultured overnight with the LnB5 T cell clone. IFN $\gamma$ was measured the following day by intracellular cytokine stain. Means and SD of triplicates from 1 of 3 experiments. Student $t$ test, ${ }^{* *} P<0.001$. (B) Experimental setup. (C) Blood samples were analyzed by flow cytometry after cell transfer and vaccination. (D) IFN $\gamma$ production by transferred LnB5 T cells, as measured by intracellular cytokine stain, was evaluated on blood samples on day 13 after T cell transfer. Shown are means with \pm SEM from 1 of 3 experiments. (E and F) One week after the second vaccination, mice received peptide-loaded and CFSE-labeled splenocytes i.v. in a 1:1 ratio. Two days after challenge, spleens of recipient mice were analyzed for the presence of differentially labeled target cells. Data representative of 2 independent experiments with 3 mice per group. (G and $\mathbf{H})$ Differentially CFSE-labeled $\mathrm{C} 57 \mathrm{BL} / 6$ and Tap1 ${ }^{-/-}$splenocytes were used as targets. Data represent means with \pm SEM pooled from 2 independent experiments with 3 mice per group. One-way ANOVA, ${ }^{*} P<0.05,{ }^{*} P<0.001$.

together, we demonstrate that TEIPP T cells can be efficiently primed in vivo by cross-presentation, resulting in properly activated $\mathrm{CD} 8^{+}$TEIPP T cells with potent killing capacities.

Effective tumor control delay by LnB5 $\mathrm{tg}$ cells. The efficient killing of surrogate target cells by LnB5 tg cells after peptide vaccination prompted us to examine the control of TAP-deficient tumor cells. To this end, we used the highly aggressive, TAP2-deficient lymphoma RMA-S. These tumors display a minimal level of MHC-I at their cell surface and are refractory to conventional antitumor cytotoxic T lymphocyte (CTL). Mice were inoculated with tumor 
A
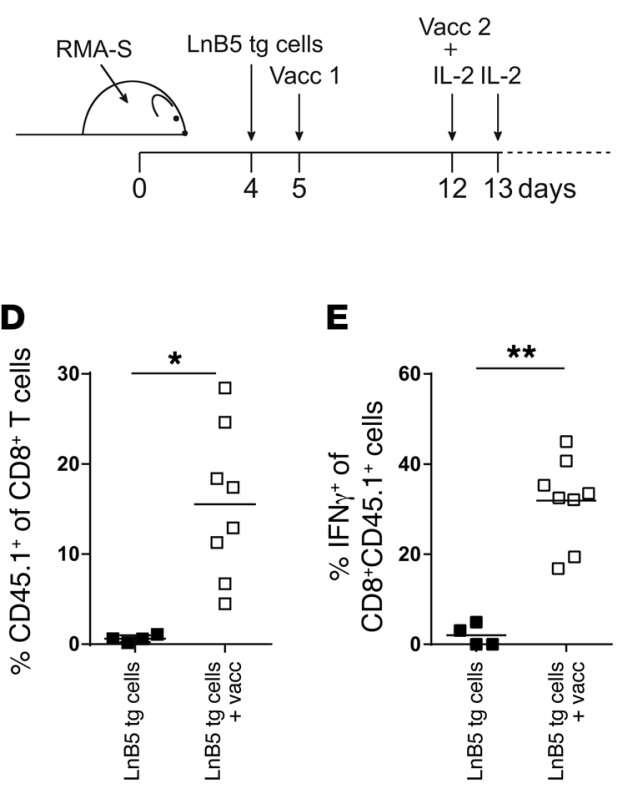

B

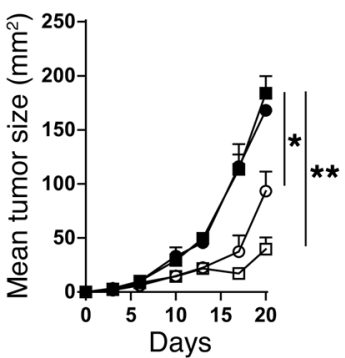

$\mathbf{F}$

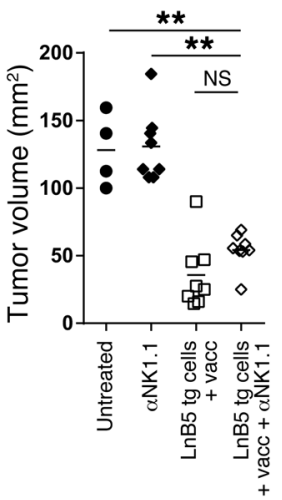

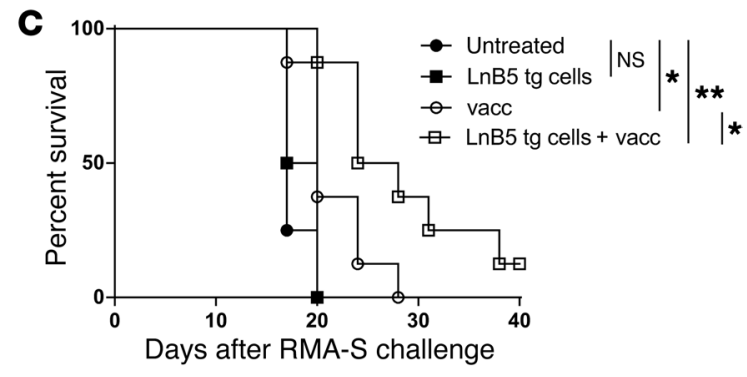

Figure 6. TEIPP T cells delay outgrowth of immune-escape tumors with TAP defect. (A) Mice were challenged with the TAP2-deficient RMA-S tumor and treated with adoptive transfer of naive LnB5 $\mathrm{tg}$ T cells and peptide vaccination when a palpable tumor was present. (B) Mean tumor size of RMA-S tumor over time; data shown from one experiment, with 4 or 8 mice per group. One-way ANOVA, ${ }^{*} P<0.05,{ }^{* *} P<0.001$. (C) Percentage of survival of mice in treatment groups. Log-Rank test, ${ }^{*} P<0.05,{ }^{* *} P<0.001$. (D and E) Blood of mice at day 18 was analyzed for proliferation and activation of $\mathrm{LnB5}$ tg $\mathrm{T}$ cells. Data from one experiment, with 4 or 8 mice per group. Student $t$ test, ${ }^{*} P<0.05$, ${ }^{* *} P<0.001$. (F) Mean tumor size of RMA-S tumor at day 15 ; NK cell depletion was started 1 day before $T$ cell transfer. One-way ANOVA, ${ }^{* *} P<0.001$.

cells, and when a palpable tumor was present, mice were treated by adoptive transfer of LnB5 tg cells and peptide vaccination according to the protocol used before (Figure 6A). Without treatment, RMA-S tumors grew out rapidly, and mice had to be sacrificed within 20 days after tumor challenge (Figure 6, B and C). Addition of LnB5 tg cells did not result in delay in tumor outgrowth, consistent with the fact that that peptide vaccination is needed to activate LnB5 tg T cells in WT hosts. T cell transfer in combination with peptide vaccination resulted in a significant delay of tumor outgrowth and survival of a quarter of the animals (Figure 6, B and C, and Supplemental Figure 2A). Peptide vaccination alone resulted in a modestly reduced tumor outgrowth, most likely due to CpG-activated NK cells. In blood of vaccinated mice, expansion and activation of LnB5 tg T cells was observed (Figure 6, D and E). We were interested in a possible contribution of NK cells in our model, since the RMA-S tumor is a well-known target for killing by these innate cells $(26,27)$. To this end, NK cells were depleted during the RMA-S tumor-treatment experiment, starting one day before T cell transfer. At day 15 after tumor challenge, mice that received LnB5 tg T cells and subsequent vaccination had a significantly reduced tumor size compared with untreated mice even in the absence of NK cells (Figure 6F). The observed reduction in tumor size was mediated by vaccination-induced stimulation of the transferred LnB5 T cells. Interestingly, TEIPP T cells and NK cells appeared to collaborate for the long-term control of RMA-S tumors (Supplemental Figure $2 \mathrm{~B}$ ). Together, these results show that TEIPP T cells can delay and control tumor outgrowth of tumors with antigen-processing defects that are otherwise resistant to antitumor CTL.

\section{Discussion}

Here we report on the thymic selection and functional behavior of $\mathrm{T}$ cells specific for self-antigens, called TEIPP, that emerge on cells with defects in the antigen-processing machinery. Our research on TEIPP antigens has thus far mainly focused on the antigens and their intracellular processing and presentation pathway $(13,14)$. There, we found that TEIPPs are derived from ubiquitously expressed housekeeping proteins, are presented as short peptides in MHC-I molecules (classical and nonclassical), and are processed via alternative routes, independent of the peptide transporter TAP (28). Although they are germline encoded, nonmutated self-antigens, TEIPP antigens are true neoantigens because they are selectively presented on the surface of cells with impaired TAP function. Therefore, TEIPPs emerge de novo in the MHC-I peptide repertoire and possess immunogenicity due to their "hidden" feature under normal conditions. In our current work, we demonstrated that the prototypic TEIPP antigen from TRH4 is not presented on tissues of the body, even in inflammatory conditions like systemic triggering of CD40. Even in these conditions of sterile inflammation, TEIPP T cells did not undergo antigendriven activation. Systemic triggering of CD40 receptors have been shown to induce massive activation of B cells, macrophages, and DCs and, moreover, lead to systemic release of immunostimulatory cytokines (24). In contrast, deficiency in the peptide transporter TAP readily induced presentation of the antigen.

Due to the "selfness" of this category of cancer antigens, the risks of autoreactivity and also tolerance induction are at hand and needed careful investigation. Here, we studied some of these issues 
using LnB5 tg mice. We found that TEIPP-specific CD8 ${ }^{+} \mathrm{T}$ cells are efficiently selected in the thymus and display a naive phenotype in the periphery. No signs of central thymic tolerance were observed. We concluded that developing TEIPP $\mathrm{T}$ cells do not encounter their cognate antigen in the thymus and are thus released into the periphery as a noncurtailed repertoire. In parallel, TEIPP T cells also appeared to remain ignorant in the periphery. Antigenic stimulation with peptide vaccines or TRH4 antigen-presenting cells (APCs) in Tap1 ${ }^{-/-}$mice did lead to strong activation of TEIPP T cells. Together, these results represent a broad therapeutic window for TEIPP antigens and the availability of an unspoiled, ignorant $\mathrm{T}$ cell repertoire that is a strong asset for exploitation of TEIPP antigens in immunotherapy of cancer. Auto-pathology to healthy tissues is not anticipated for TEIPP-targeted immunotherapy, in contrast to the exploitation of other self-antigens in immunotherapeutic approaches for cancer treatment. So-called cancer/testis antigens and cancer differentiation antigens have shown that, although a safe therapeutic window was anticipated, T cell-mediated autopathology constitutes a serious problem. Effective antitumor $\mathrm{T}$ cell responses against overexpressed differentiation antigens, like tyrosinase and gp100, have been shown to cause autopathology to the melanocytes in the conjunctiva layer of the eye and in the cochlea of the inner ear, leading to visual and hearing degeneration $(29,30)$. Obviously, these on-target adverse effects are more drastic than skin depigmentation and are clearly dose-limiting and preclude further exploitation. Similarly, the unexpected expression of MAGE-A12 protein in the brain caused unacceptable neurotoxicity in a TCR gene therapy trial, although MAGE is the classical example of a cancer/testis antigen (31). Our data indicate that the category of TEIPP cancer antigens, although being self-antigens, can best be classified in the group of viral non-self-antigens in that they are clearly foreign for the $\mathrm{T}$ cell immune system.

TEIPP $\mathrm{T}$ cells were found to be activated by vaccination with synthetic long peptides composing the minimal CD8 T cell epitope. From these results, we deduced that TAP-proficient host APCs were able to internalize these long peptides, digest, and cross-present them in MHC-I molecules in the face of the full competing peptide repertoire; thus, immunotherapy with TEIPP antigens can be exploited using this platform. We currently investigate how these host APCs manage to achieve this and which antigen processing pathway is responsible for this function.

Together, the observed characteristics of TEIPP T cells all point at an optimal window of opportunity for exploitation of these $\mathrm{T}$ cells for immunotherapy of cancers with antigen-processing defects. Deficiencies in components of the antigen-processing machinery in tumors have been correlated with poor prognosis and metastasis, and the urge to find therapies for these immune-escaped variants becomes urgent now that immunotherapy reaches clinical success $(10,32-36)$. The delayed tumor outgrowth of the aggressive MHC-I I $^{\mathrm{lo}}$ lymphoma RMA-S tumor after TEIPP T cell transfer and vaccination nicely illustrated the antitumor potency of this $\mathrm{CD}^{+} \mathrm{T}$ cell subset and provides us with tools to counteract tumors that have escaped from conventional immunotherapies. In conclusion, we show that TEIPP T cells are efficiently selected in the thymus and are not blunted by central or peripheral tolerance mechanisms, can readily be activated by vaccination, and can delay tumor out- growth of antigen-processing deficient tumor cells. This CD8 ${ }^{+}$ $\mathrm{T}$ cell subset might complement conventional therapies to prevent outgrowth of immune-escaped cancer cells.

\section{Methods}

Cell lines and mice. The tumor cell lines RMA, RMA-S (TAP2-deficient), RMA-S.B7.1 (RMA-S transfected with mouse CD80 gene), and DC line D1 have been described before $(13,16)$. C57BL/6 and Tap1 ${ }^{-/-}$DCs were generated from BM from $\mathrm{C} 57 \mathrm{BL} / 6$ and $\mathrm{Tap1}^{-/-}$mice, respectively, and were cultured for 1 week in the presence of IL-4 and GM-CSF. The generation and culture of TEIPP T cell clone LnB5, with specificity for the TRH4-derived peptide MCLRMTAVM in the context of $\mathrm{H}-2 \mathrm{D}^{\mathrm{b}}$, has been previously described (13). All cells were cultured in complete IMDM medium (Invitrogen) containing $8 \%$ heat-inactivated FCS (Invitrogen), $100 \mathrm{U} / \mathrm{ml}$ penicillin, $100 \mu \mathrm{g} / \mathrm{ml}$ streptomycin, and $2 \mathrm{mM} \mathrm{L}$-glutamine (Invitrogen) at $37^{\circ} \mathrm{C}$ in humidified air with $5 \%$ $\mathrm{CO}_{2}$. C57BL/6 mice were purchased from Charles River Laboratories. The Tap1-- mice (catalog 00294) and the OT-I LnB5 tg mice (catalog 003831), containing the $\mathrm{OVA}_{257-264} / \mathrm{K}^{\mathrm{b}}$-restricted TCRs, were derived from The Jackson Laboratory. The pmel LnB5 tg mice, containing the $\mathrm{gp} 100_{25-33} / \mathrm{D}^{\mathrm{b}}$ - specific TCRs, were a gift from N.P. Restifo (National Cancer Institute, Bethesda, Maryland, USA). Mice were housed in individually ventilated cages and used at 6-12 weeks of age.

Generation of LnB5 $\mathrm{tg}$ mice. The LnB5 TCR transgenic mouse strain was generated by transgenesis of the TCR $\alpha$ and TCR $\beta$ genes of the LnB5 T cell clone, specific for the TRH4/ $\mathrm{D}^{\mathrm{b}}$ complex. Cloning and sequencing of the TCR chains identified the $\alpha$ chain as composed by TRAV9N-3*01 and TRAJ15*01 and the $\beta$ chain composed by $\mathrm{V} 13-2^{*} 01, \mathrm{D} 1^{*} 01$, and $\mathrm{J} 1-4^{*} 02$, according to the ImMunoGeneTics nomenclature (Table 1 and www.imgt.org). The Tcra and Tcrb chains were separately cloned into pCRII-TOPO plasmid vectors (Invitrogen) using reverse transcription PCR (RT-PCR). Validation of correct TCR cloning was performed by retroviral transduction of the TCR in C57BL/6 splenocytes using pMX vectors (Ton Schumacher, NKI). Next, the 2 chains were separately cloned into VA-hCD2 vectors (37), the inserts of which were subsequently injected in C57BL/6 oocytes to produce transgenic mice. DNA from tails of founder mice was analyzed by PCR for presence of the constructs, using the forward primer in the CD2 cassette: $5^{\prime}$-GGTGTGGACTCCACCAGTCTCACTTC- ${ }^{\prime}$ and the reverse primer in the TCR $\alpha$ : 5'-TAACTGGTACACAGCAGG-3' or TCR $\beta$ region: 5'-CAAACAAGGAGAGACCTTG-3' (Invitrogen). Blood samples of transgenic offspring mice were screened for presence of TCR transgenic T cells using specific antibodies to TCR V $\alpha 3$ (clone RR3-16, BioLegend) and TCR V $\beta 8$ (clone KJ-16-133.18, BioLegend).

Adoptive cell transfer, vaccination, and in vivo cytotoxicity assay. For T cell transfer assays, single cell suspensions were made by mechanical disruption of spleen and lymph nodes of LnB5 tg mice. Cells were passed through nylon wool to enrich for T cells, and $3 \times 10^{6} \mathrm{CD} 8^{+} \mathrm{T}$ cells were i.v. injected in $200 \mu \mathrm{l}$ PBS in recipient mice. Peptide vaccination was performed at day 1 and day 8 after T cell transfer with $50 \mu \mathrm{g}$ of the proline-modified 9-mer TRH4 peptide (MCPRMTAVM) $(38,39)$ or $150 \mu \mathrm{g}$ of the 21-mer TRH4 peptide (AWWQLDSSILLCMCPRMTAVM). Peptides were s.c. injected in $200 \mu$ PBS containing $20 \mu \mathrm{g}$ of TLR9 ligand CpG (ODN 1826, InvivoGen). At day 8 and 9 after $\mathrm{T}$ cell transfer, mice received 600,000 IU IL-2 in $100 \mu \mathrm{l}$ PBS intraperitoneal. For in vivo cytotoxicity assays, mice were challenged 
1 week after the second vaccination with CFSE-loaded splenocytes pulsed with either the TRH4 peptide or the $\mathrm{D}^{\mathrm{b}}$-binding control peptide Ad10 (SGPSNTPPEI) (16). Alternatively, mice were challenged with C57BL/6 splenocytes (not peptide loaded) and splenocytes from $\mathrm{Tap1}^{-/-}$mice, differentially labeled with CFSE. To exclude NK cell-mediated killing, mice were depleted of NK cells with $100 \mu \mathrm{g}$ anti-NK1.1 (clone PK136, Bioceros B.V.) in $200 \mu$ l PBS i.p. at days 2 and 5 before injection of target cells. Two days after challenge, spleens were harvested and analyzed by flow cytometry.

Flow cytometry analyses. For flow cytometry analysis, single cell suspensions were stained in 0.1\% BSA/PBS with antibodies for CD4 (clone RM4-5), CD8 (clone 53.6-7), CD3 (clone 145-2C11), TCR $\beta$

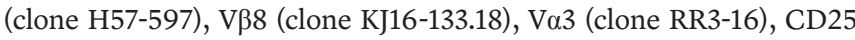
(clone PC61), CD62L (clone MEL-14), NKG2A (clone 16A11), NKG2D (clone CX5) (all from BioLegend), NK1.1 (clone PK136), CD49b (clone DX5), CD69 (clone H1.2F3), CD122 (clone TM-b1), Ly49h (clone 3D10), KLRG1 (clone 2F1) (all from eBioscience), CD94 (clone 18d3), or Ly6C (clone HK1.4) (both from BD Biosciences). Antibodies were derived from eBioscience, BioLegend, or BD Biosciences. Intracellular cytokine staining was performed using the ICS kit from BioLegend according to manufacturer's protocol. Cells were permeabilized for 20 minutes with the fixation buffer on ice, washed twice in $1 \times$ permeabilization/washing buffer, and thereafter stained for IFN $\gamma$ (clone XMG1.2, BioLegend). Intracellular staining of the transcription factor Helios (clone 22F6, BioLegend) was performed using the FoxP3 staining kit according to manufacturer's protocol (eBioscience). In short, cells were stained for cell surface markers, permeabilized for $30 \mathrm{~min}$ utes on ice, and subsequently stained for Helios. Cells were analyzed on a FACS Calibur or Fortessa (BD Biosciences), and all analysis was performed using FlowJo (Tree Star Inc.).

In vitro stimulations and cross-presentation experiments. For in vitro $\mathrm{T}$ cell assays with naive transgenic LnB5 $\mathrm{T}$ cells, spleen and lymph nodes were isolated, and $\mathrm{CD}^{+} \mathrm{T}$ cells were enriched using nylon wool, purified using the $\mathrm{CD}^{+}$enrichment kit (BD Biosciences), and labeled with $5 \mu \mathrm{M}$ CFSE. A total of 100,000 cells were put in a 96-well plate with various stimuli in the presence of $10 \mathrm{CU}$ IL-2/ml. For $\alpha \mathrm{CD} 3 / \alpha \mathrm{CD} 28$ stimulation, wells of a 96 -well plate were coated overnight with $0.5 \mu \mathrm{g} / \mathrm{ml} \alpha \mathrm{CD} 3$ (clone 145-2C11, BD Biosciences) in $100 \mu \mathrm{l}$ PBS. The next day, coated wells were washed with medium, and cells were added with $2 \mu \mathrm{g} / \mathrm{ml} \alpha \mathrm{CD} 28$ (clone 37.51, BioLegend). For peptide stimulation, $1 \mu \mathrm{g} / \mathrm{ml}$ peptide was added to the wells, and at day 1 and day 2 after start of the experiment, $1 \mu$ l of $1 \mu \mathrm{g} / \mathrm{ml}$ peptide solution was added to the corresponding well. Three days after start of the culture, cells were analyzed by flow cytometry and supernatants were analyzed for cytokine release measured by IFN $\gamma$ ELISA as described previously or by Cytokine Bead Array assay (BD Biosciences).

For cross-presentation experiments, DC line D1 was loaded for 5 hours with 21-mer long TRH4 peptide (HPLC purified to >95\%). Cells were thereafter washed extensively. D1 cells $(50,000)$ were cocultured with 50,000 LnB5 T cells in the presence of GolgiPlug (BD Biosciences). The following day, intracellular cytokine was performed as described previously.

Tumor experiments. C57BL/6 mice were inoculated with $2 \times 10^{6}$ RMA-S cells in $200 \mu \mathrm{l} 0.1 \%$ BSA/PBS s.c. in the left flank. Four days later, $3 \times 10^{6}$ nylon wool-purified splenocytes from LnB5 tg mice were injected i.v. At days 5 and 12, mice were vaccinated with $50 \mu \mathrm{g}$ of the (short) proline-modified TRH4 peptide with $20 \mu \mathrm{g}$ CpG in $200 \mu \mathrm{l}$ PBS s.c. in the opposite flank. Additionally, mice received 100,000 $\mathrm{U}$ IL-2 at days 12 and 13. Tumor sizes were measured using a caliper, and mice were sacrificed when the tumor size reached $2,000 \mathrm{~mm}^{3}$. In the NK cell-depletion experiment, NK cells were depleted using 100 $\mu \mathrm{g}$ PK136-depleting antibody, starting the day before $\mathrm{T}$ cell transfer. Depletion was maintained every 3-4 days.

Statistics. Statistical analyses were done in GraphPad Prism, version 6.0. In tumor experiments, Kaplan Meier survival curves of mice was analyzed using log-rank assay. Additional statistical methods are described in the legend. $P$ values $<0.05$ were considered statistically significant.

Study approval. All animal experiments were approved by the ethics committee of the LUMC.

\section{Author contributions}

EMD, SHVDB, and TVH developed the concept and designed experiments. EMD, MS, BJQ, and CCO conducted experiments and analyzed data. EMD, FO, AA, SHVDB, and TVH interpreted results. EMD and TVH wrote the manuscript.

\section{Acknowledgments}

We would like to thank Ramon Arens for critically reading the manuscript, Jan-Wouter Drijfhout for generation of the peptides, and Kees Franken for generation of tetramers. This project was supported by the Dutch Cancer Society Fund (UL2010-4785 to T. van Hall and S.H. van der Burg), and A. Achour was supported by the Swedish Cancer Society and Swedish Research Council.

Address correspondence to: Thorbald van Hall, Department of Clinical Oncology, K1-P, Leiden University Medical Center, Albinusdreef 2, 2333 ZA Leiden, The Netherlands. Phone: 31.71.5266945; E-mail: T.van_Hall@lumc.nl.
1. Hodi FS, et al. Improved survival with ipilimumab in patients with metastatic melanoma. $N$ Engl J Med. 2010;363(8):711-723.

2. Mellman I, Coukos G, Dranoff G. Cancer immunotherapy comes of age. Nature. 2011;480(7378):480-489.

3. Wolchok JD, et al. Nivolumab plus ipilimumab in advanced melanoma. $N$ Engl J Med. 2013;369(2):122-133.

4. Sharma P, Allison JP. Immune checkpoint targeting in cancer therapy: toward combination strategies with curative potential. Cell.
2015;161(2):205-214.

5. van der Sluis TC, et al. Vaccine-induced tumor necrosis factor-producing $\mathrm{T}$ cells synergize with cisplatin to promote tumor cell death. Clin Cancer Res. 2015;21(4):781-794.

6. Welters MJ, et al. Success or failure of vaccination for HPV16-positive vulvar lesions correlates with kinetics and phenotype of induced T-cell responses. Proc Natl Acad Sci US A. 2010;107(26):11895-11899.

7. Nobuoka D, Yoshikawa T, Sawada Y, Fujiwara T, Nakatsura T. Peptide vaccines for hepato- cellular carcinoma. Hum Vaccin Immunother. 2013;9(1):210-212.

8. Coulie PG, Van den Eynde BJ, van der Bruggen $P$, Boon T. Tumour antigens recognized by $\mathrm{T}$ lymphocytes: at the core of cancer immunotherapy. Nat Rev Cancer. 2014;14(2):135-146.

9. Garrido F, Cabrera T, Aptsiauri N. "Hard" and "soft" lesions underlying the HLA class I alterations in cancer cells: implications for immunotherapy. Int J Cancer. 2010;127(2):249-256.

10. Carretero R, et al. Analysis of HLA class I expression in progressing and regressing metastatic 
melanoma lesions after immunotherapy. Immunogenetics. 2008;60(8):439-447.

11. Andersson E, et al. Correlation of HLA-A02* genotype and HLA class I antigen down-regulation with the prognosis of epithelial ovarian cancer. Cancer Immunol Immunother. 2012;61(8):1243-1253.

12. Verweij MC, et al. Inhibition of mouse TAP by immune evasion molecules encoded by non-murine herpesviruses. Mol Immunol. 2011;48(6-7):835-845.

13. Oliveira CC, et al. New role of signal peptide peptidase to liberate $\mathrm{C}$-terminal peptides for MHC class I presentation. J Immunol. 2013;191(8):4020-4028.

14. Oliveira CC, Querido B, Sluijter M, Derbinski J, van der Burg SH, van Hall T. Peptide transporter TAP mediates between competing antigen sources generating distinct surface MHC class I peptide repertoires. Eur JImmunol. 2011;41(11):3114-3124.

15. Seidel UJ, Oliveira CC, Lampen MH, Hall T. A novel category of antigens enabling CTL immunity to tumor escape variants: Cinderella antigens. Cancer Immunol Immunother. 2012;61(1):119-125.

16. van Hall T, et al. Selective cytotoxic T-lymphocyte targeting of tumor immune escape variants. Nat Med. 2006;12(4):417-424.

17. Overwijk WW, et al. Tumor regression and autoimmunity after reversal of a functionally tolerant state of self-reactive $\mathrm{CD} 8^{+} \mathrm{T}$ cells. JExp Med. 2003;198(4):569-580.

18. Clarke SR, Barnden M, Kurts C, Carbone FR, Miller JF, Heath WR. Characterization of the ovalbumin-specific TCR transgenic line OT-I: MHC elements for positive and negative selection. Immunol Cell Biol. 2000;78(2):110-117.

19. Schonrich G, et al. Down-regulation of T cell receptors on self-reactive $\mathrm{T}$ cells as a novel mechanism for extrathymic tolerance induction. Cell. 1991;65(2):293-304.

20. Ross EM, Bourges D, Hogan TV, Gleeson PA, van Driel IR. Helios defines T cells being driven to tolerance in the periphery and thymus. Eur $J$ Immunol. 2014;44(7):2048-2058.

21. Daley SR, Hu DY, Goodnow CC. Helios marks strongly autoreactive $\mathrm{CD} 4^{+} \mathrm{T}$ cells in two major waves of thymic deletion distinguished by induction of PD-1 or NF-кB. JExp Med. 2013;210(2):269-285.

22. Hernandez J, Aung S, Redmond WL, Sherman LA. Phenotypic and functional analysis of CD8(+) T cells undergoing peripheral deletion in response to cross-presentation of self-antigen. JExp Med. 2001;194(6):707-717.

23. Miller JF, Kurts C, Allison J, Kosaka H, Carbone F, Heath WR. Induction of peripheral CD8 ${ }^{+} \mathrm{T}$-cell tolerance by cross-presentation of self antigens. Immunol Rev. 1998;165:267-277.

24. Fransen MF, Sluijter M, Morreau H, Arens R, Melief CJ. Local activation of CD8 T cells and systemic tumor eradication without toxicity via slow release and local delivery of agonistic CD40 antibody. Clin Cancer Res. 2011;17(8):2270-2280.

25. Oliveira CC, et al. The nonpolymorphic MHC $\mathrm{Q} a-1 \mathrm{~b}$ mediates $\mathrm{CD} 8^{+} \mathrm{T}$ cell surveillance of antigen-processing defects. JExp Med. 2010;207(1):207-221.

26. Ni J, Miller M, Stojanovic A, Garbi N, Cerwenka A. Sustained effector function of IL-12/15/18-preactivated NK cells against established tumors. JExp Med. 2012;209(13):2351-2365.

27. Ardolino M, et al. Cytokine therapy reverses NK cell anergy in MHC-deficient tumors. JClin Invest. 2014;124(11):4781-4794.

28. Oliveira CC, van Hall T. Alternative antigen processing for MHC Class I: multiple roads lead to Rome. Front Immunol. 2015;6:298.

29. Palmer DC, et al. Effective tumor treatment targeting a melanoma/melanocyte-associated antigen triggers severe ocular autoimmunity. Proc Natl Acad Sci U S A. 2008;105(23):8061-8066.
30. Seaman BJ, et al. Audiovestibular dysfunction associated with adoptive cell immunotherapy for melanoma. Otolaryngol Head Neck Surg. 2012;147(4):744-749.

31. Morgan RA, et al. Cancer regression and neurological toxicity following anti-MAGE-A3 TCR gene therapy. J Immunother. 2013;36(2):133-151.

32. Seliger B. The link between MHC class I abnormalities of tumors, oncogenes, tumor suppressor genes, and transcription factors. J Immunotoxicol. 2014;11(4):308-310.

33. Khong HT, Restifo NP. Natural selection of tumor variants in the generation of "tumor escape" phenotypes. Nat Immunol. 2002;3(11):999-1005.

34. Seliger B, et al. Association of HLA class I antigen abnormalities with disease progression and early recurrence in prostate cancer. Cancer Immunol Immunother. 2010;59(4):529-540.

35. Seliger B, Cabrera T, Garrido F, Ferrone S. HLA class I antigen abnormalities and immune escape by malignant cells. Semin Cancer Biol. 2002;12(1):3-13.

36. Ferris RL, Whiteside TL, Ferrone S. Immune escape associated with functional defects in antigen-processing machinery in head and neck cancer. Clin Cancer Res. 2006;12(13):3890-3895.

37. Zhumabekov T, Corbella P, Tolaini M, Kioussis D. Improved version of a human $\mathrm{CD} 2$ minigene based vector for $\mathrm{T}$ cell-specific expression in transgenic mice. JImmunol Methods. 1995;185(1):133-140.

38. Uchtenhagen $\mathrm{H}$, et al. Proline substitution independently enhances $\mathrm{H}-2 \mathrm{D}(\mathrm{b})$ complex stabilization and TCR recognition of melanoma-associated peptides. Eur JImmunol. 2013;43(11):3051-3060.

39. van Stipdonk MJ, Badia-Martinez D, Sluijter M, Offringa R, van Hall T, Achour A. Design of agonistic altered peptides for the robust induction of CTL directed towards $\mathrm{H}-2 \mathrm{Db}$ in complex with the melanoma-associated epitope gp100. Cancer Res. 2009;69(19):7784-7792. 